\title{
Electrocoagulation of Methylene Blue using Graphene Oxide as Adsorbent
}

\author{
A. Lakshmi* \\ Department of Chemistry, St. Mary's College (Autonomous), Thoothukudi - 628 001, Tamilnadu, India.
}

\section{A R T I C L E D E T A I L S}

Article history:

Received 18 November 2019

Accepted 01 December 2019

Available online 10 December 2019

\section{Keywords:}

Electro Coagulation

Dyes

Industrial Pollutants

\begin{abstract}
A B S T R A C T
This work has been carried out to minimize environmental pollution by investigation of efficient electrocoagulation of methylene blue by aluminum electrode cell setup using graphene oxide as adsorbent. The efficiency of dye removal was evaluated by the absorbance of methylene blue at $665 \mathrm{~nm}$. The operating parameters for electrocoagulation such as current density $\left(10-30 \mathrm{~mA} / \mathrm{cm}^{2}\right)$, electrolysis time (5-20 minutes), $\mathrm{pH}$ of the medium (2 to 10 ), stirring speed (150-350 rpm), inter electrode distance $(0.8$ to $2 \mathrm{~cm})$ and $\mathrm{NaCl}$ concentration $(1.5-5.0 \mathrm{~g} / \mathrm{L})$ were optimized and found to be $30 \mathrm{~mA} / \mathrm{cm}^{2}, 20 \mathrm{~min}$, $\mathrm{pH} 7.0,300 \mathrm{rpm}, 2 \mathrm{~cm}$ and $5 \mathrm{~g} / \mathrm{L}$ respectively. The results showed that the dye removal efficiency was enhanced to $99 \%$ by the addition of graphene oxide. The result of the present research work can be useful for an efficient large-scale treatment of industrial effluents contaminated with methylene blue.
\end{abstract}

\section{Introduction}

Modern dyes have a multiple array and they are often intended to be fashioned to resist the breakdown of long-term exposure to sunlight, water, and other atrocious conditions, and thus making the management of dye wastewater more complex. The effluents from textile plants contain portions of dyes, which are important water pollution sources. The dyes are deeply colored, multicomponent, and consume dissolved oxygen, and destroy aquatic life. Moreover, some dyes and their degradation products may be carcinogens and toxic, Therefore, it is necessary to treat the dyes before disposal. Many dyes are difficult to decolourise due to their complex structure and synthetic origin. A wide range of methods has been developed for the removal of synthetic dyes from waters and wastewaters to decrease their impact on the environment. Electrocoagulation is an effective electrochemical approach for the treatment of dye effluent. Among various processes, electrocoagulation is a latest innovation for wastewater treatment with high removal efficiency for several pollutants; oil and grease, metal, nutrient, turbidity and colour [1,2]. The electrocoagulation process offers an easy, trustworthy, and commercial method for the treatment of wastewater without the need for additional chemicals, and thus, without the production of secondary pollution [3-6]. It also reduces the amount of sludge which needs to be disposed [7]. The separation by electrocoagulation of pollutants such as hydrocarbons $[8,9]$, dyes [10-13], heavy metal ions [14,15], leachate [16], and various other ions such as boron [17] and fluorine [18] have been reported. The reduction in COD during the electrocoagulation of methylene blue (MB) and eosin yellowish (EY) in presence of $\mathrm{NaCl}$ as electrolyte was reported as efficient tool [19]. There was an efficiency enhancement in removal of methylene blue dye using an electromagnetic field i.e. iron electrode during the electrocoagulation process [20]. The effect of operational parameters and mechanism of removal of methylene blue dye by electrocoagulation was studied and maximum dye removal efficiency was found to be $99.37 \%$ [21]. Taguchi method was applied to determine the optimum removal of methylene blue (MB) using iron electrodes [22]. Decolorization of methylene blue dye waste by electrocoagulation technique was studied and found that the energy consumption for dye removal using aluminum and iron electrodes was 0.634 and $0.375 \mathrm{~kW} . \mathrm{h} / \mathrm{m}^{3}$, respectively [23]. In this present study the synthetic dye methylene blue was selected. The parameters such as $\mathrm{pH}$, TSS, BOD and COD were analyzed for the synthetic dye effluent before and after electrocoagulation. The spectral characterizations such as FT-IR and UV-Vis characterisation of the samples were done. Electrolytic cell reactor set up for electrocoagulation

process was developed and the removal efficiency of dye was compared with effluent having graphene oxide as adsorbent.

\section{Experimental Methods}

\subsection{Equipment Setup}

The electrocoagulation unit mainly consists of aluminum sheet as cathode, anode and a DC power supply. Working volume of the electrochemical reactor was around $0.25 \mathrm{~L}$, inter electrode distance was 1 $\mathrm{cm}$ and the effective electrodes area was approximately $18 \mathrm{~cm}^{2}$. A digital DC source (PICO, 0-30 V, 0-5 A CVCC MODE) was used to supply the power to the ECF system. A magnetic stirrer was used to provide thorough mixing to the solution. Synthetic textile dye effluent was prepared by mixing $0.1 \mathrm{~g}$ of the methylene blue dye in 1 liter of distilled water along with starch (1 $\mathrm{mg} / \mathrm{L}), \mathrm{Na}_{2} \mathrm{SO}_{4}(1 \mathrm{mg} / \mathrm{L})$, and $\mathrm{Na}_{2} \mathrm{HPO}_{4}(1 \mathrm{mg} / \mathrm{L})$. Then it was placed on a hot plate equipped with a magnetic stirrer at $80{ }^{\circ} \mathrm{C}$ for 1 hour. After attaining the uniform concentration, the samples were cooled and packed in air tight containers. The parameters such as pH, TSS, COD, BOD of the samples were analyzed in Global lab and consultancy services, Salem, Tamilnadu and the reports are discussed here.

\subsection{Procedure}

Electrolysis is a process in which oxidation and reduction reactions take place when electric current is applied to an electrolytic solution. Electrocoagulation is based on dissolution of the electrode material used as an anode. This so called "sacrificial anode" produces metal ions which act as coagulant agents in the aqueous solution in situ. At its simplest, an electrocoagulation system consists of an anode and a cathode made of metal plates, both sub- merged in the aqueous solution being treated. The electrodes are usually made of aluminum, iron, or stainless steel (SS), because these metals are cheap, readily available, proven effective, and non-toxic [24].

During EC, the following main reactions take place at the electrodes.

Anodic reactions,

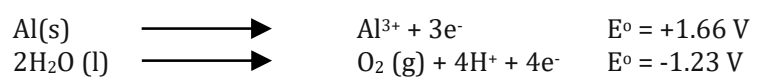

Cathodic reaction,

$$
2 \mathrm{H}_{2} \mathrm{O}+2 \mathrm{e}^{-} \longrightarrow \quad \mathrm{H}_{2}(\mathrm{~g})+2 \mathrm{OH}^{-} \quad \mathrm{E}^{\mathrm{o}}=-0.83 \mathrm{~V}
$$

Additionally, when chloride is present and the anode potential is sufficiently high, the following reactions may take place in the EC cell. 


\begin{tabular}{|c|c|c|}
\hline $\begin{array}{l}2 \mathrm{Cl}^{-} \\
\mathrm{Cl}_{2}+\mathrm{H}_{2} \mathrm{O} \\
\mathrm{HClO}\end{array}$ & $\begin{array}{l}\mathrm{Cl}_{2}+2 \mathrm{e}^{-} \\
\mathrm{HClO}+\mathrm{H}^{+} \mathrm{Cl}^{-} \\
\mathrm{H}^{+}+\mathrm{OCl}^{-}\end{array}$ & $\begin{array}{l}E^{0}=-1.36 V \\
E^{0}=-0.93 V\end{array}$ \\
\hline
\end{tabular}

The formation of active chlorine species $\left(\mathrm{Cl}_{2}, \mathrm{HClO}, \mathrm{OCl}-\right)$ enhances the performance of the $\mathrm{EC}$ reactor through oxidation reactions.

The methylene blue dye solution of $0.25 \mathrm{~L}$ and concentration of 100 ppm was added to the electrocoagulation reactor system. Then the operating factors of current density $\left(10-30 \mathrm{~mA} / \mathrm{cm}^{2}\right)$, electrolysis time (520 minutes), $\mathrm{pH}$ of the medium (2 to 10 ), stirring speed (150-350 rpm), inter electrode distance ( 0.8 to $2 \mathrm{~cm}$ ) and $\mathrm{NaCl}$ concentration (1.5-5.0 g/L) were varied. The temperature was maintained $25{ }^{\circ} \mathrm{C}$. At the end of experiments, the solution was centrifuged to remove the sludge. The solution was centrifuged and the absorbance was measured by UV-visible spectrophotometer (Deep Vision UV-VIS single beam spectrophotometer) at $665 \mathrm{~nm}$. The efficiency of dry removal was calculated using Eq.(1).

Efficiency (\%) = 1- (final absorbance / initial absorbance) $\mathrm{x} 100$

\section{Results and Discussion}

\subsection{Analysis of $p H, T S S, C O D$ and BOD}

The parameters such as $\mathrm{pH}$, TSS, COD and BOD of the sample was analyzed and shown in Table 1 . The $\mathrm{pH}$ level describes the amount of alkalinity or acidity of water. The $\mathrm{pH}$ of the sample was tested and found to be almost neutral. Total suspended solids (TSS) are the dry-weight of suspended particles that are not dissolved in the water sample that can be trapped by a filter that is analyzed using a filtration apparatus. The sample exhibited the values less than $5 \mathrm{mg} / \mathrm{L}$. The chemical oxygen demand (COD) test is used to measure the quantity of organic compounds in a water sample. It measures the capacity of water to consume oxygen during the decomposition of organic matter and the oxidation of inorganic chemicals such as ammonia and nitrate. The COD behavior of the synthetic dye effluents was found to be $60 \mathrm{mg} / \mathrm{L}$. Biochemical oxygen demand (BOD) also called biological oxygen demand is the amount of dissolved oxygen needed by aerobic biological organisms to break down organic material present in a given water sample at certain temperature over a specific time period. BOD character of the synthetic dye effluent was determined by incubating the water sample with aerobic microorganisms on a three-day incubation period at $27^{\circ} \mathrm{C}$. The BOD of the synthetic dye effluents was found to be $19 \mathrm{mg} / \mathrm{L}$. Results of the parameters after electrocoagulation has been reported in Table 1.

Table $1 \mathrm{pH}$, TSS, COD and BOD characteristics of the sample

\begin{tabular}{lllll}
\hline Sample & $\mathrm{pH}$ & $\mathrm{TSS}(\mathrm{mg} / \mathrm{L})$ & $\mathrm{COD}(\mathrm{mg} / \mathrm{L})$ & BOD $(\mathrm{mg} / \mathrm{L})$ \\
\hline Methylene blue solution & 7.36 & $<5$ & 60 & 19 \\
$\begin{array}{l}\text { Methylene blue solution } \\
\text { after coagulation }\end{array}$ & 6.78 & 36 & 438 & 1320 \\
\hline
\end{tabular}

\subsection{UV-Visible Behavior of the Synthetic Dye Effluent Samples}

The UV- Visible spectral behavior of the effluent was studied using JASCO V-530 spectrophotometer using a $1 \mathrm{~cm}$ quartz cuvette filled with the samples. The peak around 347 corresponds to the $n \rightarrow \pi^{*}(N=N)$ in dye molecules. The peaks present around $220-264 \mathrm{~nm}$ is due to $\pi \rightarrow \pi^{*}$ transition of the benzenoid rings present in the dye molecule (Fig. 1). Since the synthetic dye effluent was coloured there will be interaction of radiation from the visible part $(\lambda=380-720 \mathrm{~nm})$ of the electromagnetic spectrum with a chemical species in a dye molecule. Thus, in UV spectrum of the sample strong intense band appears in the visible region.

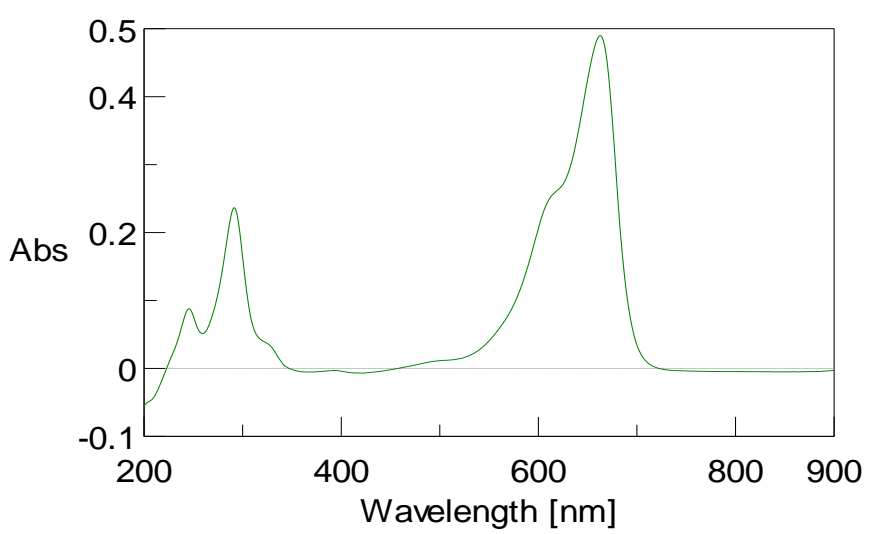

Fig. 1 UV-Vis spectral behavior of the methylene blue https://doi.org/10.30799/jespr.187.19050406

\subsection{FT-IR Spectral Behavior of the Synthetic Dye Effluent Samples}

The spectrum of sample 1 was given in Fig. 2 . The methylene blue is a non azo dye. The band at 1635 and $2132 \mathrm{~cm}^{-1}$ is due to the presence of some functional groups like $-\mathrm{CH}_{2}$ - and $-\mathrm{CH}_{3}$ respectively. The bands due to the aromatic region in the range of $1400-1600 \mathrm{~cm}^{-1}$ are also significant as azo bond stretching appears between the bands of the aromatic region. The stretching of aromatic region is prominent and strong. The absorption band of the azo chromophore is clearly distinct from the $\mathrm{C}=\mathrm{C}$ absorption bands which are quite evident in their spectrum. The azo absorption bands were sited between $1500 \mathrm{~cm}^{-1}$ and $1700 \mathrm{~cm}^{-1}$. Due to aromatic region, the higher energy bands appeared from $1590 \mathrm{~cm}^{-1}$ to $1619 \mathrm{~cm}^{-1}$. The broad band around $3100 \mathrm{~cm}^{-1}$ can be referred to the $\mathrm{N}-\mathrm{H}$ stretching vibration.

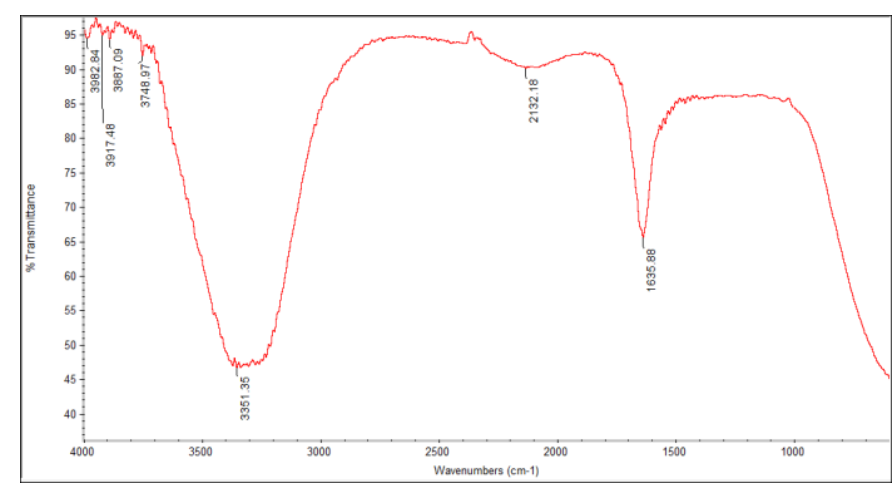

Fig. 2 FTIR spectrum of methylene blue synthetic water

\subsection{Analysis of Dye Removal Efficiency}

\subsubsection{Effect of Current Density}

The initial absorbance spectra of methylene blue solution presented the highest peak at $665 \mathrm{~nm}$ (Fig. 1), thus the reduction of the highest peak was referred for the dye removal efficiency. After treatment by EC the absorbance was measured at $665 \mathrm{~nm}$ using a UV-VIS spectrophotometer. The peak at $665 \mathrm{~nm}$ decreased from 0.5 absorbance at the initial to 0.3 absorbance at the current density of $10 \mathrm{~mA} / \mathrm{cm}^{2}$, and further decreased to 0.2 and 0.1 at the higher current densities (Fig. 3). From Fig. 3, it is evident that the dye removal efficiency was increased by increasing current densities as linear relation. The efficiency was $58 \%$ at $10 \mathrm{~mA} / \mathrm{cm}^{2}$ and increased to $83 \%$ at $20 \mathrm{~mA} / \mathrm{cm}^{2}$ and reached the maximum of $92 \%$ at 30 $\mathrm{mA} / \mathrm{cm}^{2}$. This is because a large amount of aluminium hydroxide particles (i.e., $\mathrm{Al}(\mathrm{OH})_{3}$ ) are generated at the higher current densities. The aluminium hydroxide particles act as coagulant to destabilize the colloid particles of dye, and remove the destabilized dye from the water $[25,26]$.

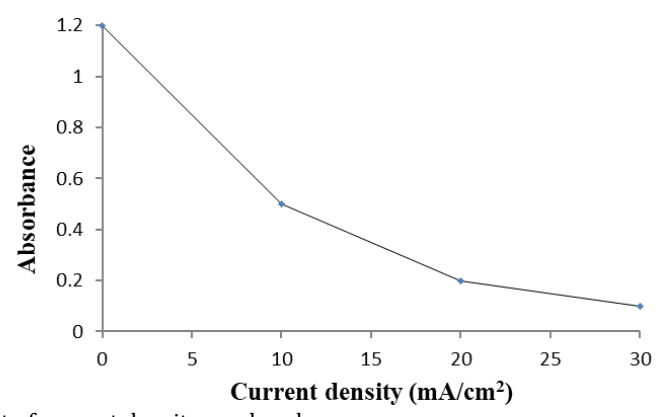

Fig. 3 Effect of current density on absorbance

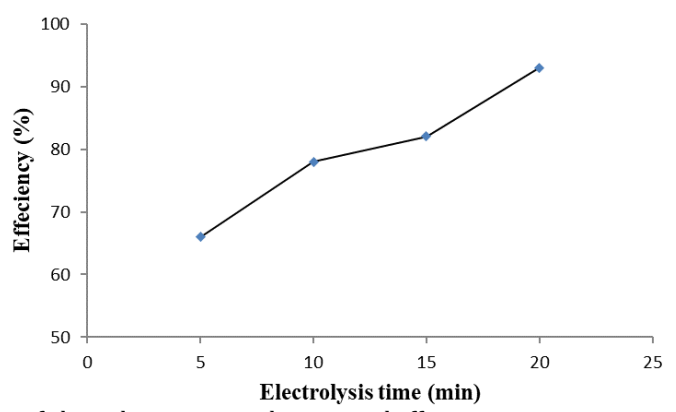

Fig. 4 Effect of electrolysis time on dye removal efficiency

\subsubsection{Effect of Electrolysis Time}

At various electrolysis times, the dye removal efficiency was increased by increasing electrolysis times as exponential relation. The efficiency was 
sharply increased to $66 \%$ at 5 minutes, and continuously increased at the longer electrolysis times (Fig. 4). The efficiency reached $78 \%$ at 10 minutes, then slightly increased to $82 \%$ at 15 minutes and reached its maximum of $93 \%$ at 20 minutes. The longer electrolysis times causes high sludge formation and $\mathrm{Al}$ electrode degradation occurs. This prevents the chemical interaction during coagulation process and increase the energy consumption.

\subsubsection{Effect of $p H$}

To study the effect of initial $\mathrm{pH}$ of the solution on the removal by the EC process, the $\mathrm{pH}$ was varied from 2 to 10 (Fig. 5). It has been observed that $\mathrm{pH}$ has not much significance in the color removal efficiency. Therefore, optimum pH value was considered as 7 which is neutral. Fig. 5 shows the percentage removal of color by varying initial $\mathrm{pH}$ of the solution. At $\mathrm{pH} 7$, aluminum hydroxide being amphoteric easily precipitated whereas it does not precipitate at very low $\mathrm{pH}$. At higher $\mathrm{pH}$, efficiency reduces because of the formation of new aluminum complex $\mathrm{Al}(\mathrm{OH})_{4}{ }^{-}$which was soluble and coagulates poorly and affects the coagulation process.

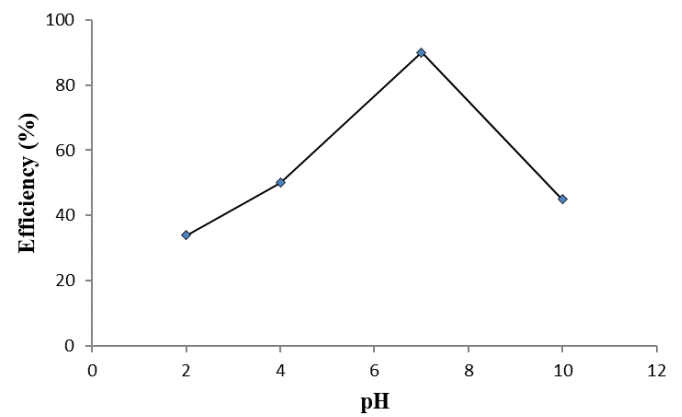

Fig. 5 Effect of $\mathrm{pH}$ on dye removal efficiency

\subsubsection{Effect of $\mathrm{NaCl}$ Concentration}

Concentration of $\mathrm{NaCl}$ was varied from 1 to $5 \mathrm{~g} / \mathrm{L}$, the dye removal efficiency was in the range between $80-92 \%$ (Fig. 6). NaCl played a role as conductive solution, and without $\mathrm{NaCl}$ addition the chemical reaction does not takes place in the EC system. Efficiency increases slightly when the concentration of $\mathrm{NaCl}$ increases. At the end of experiments, the surface of $\mathrm{Al}$ electrodes was decayed to produce the aluminium ions and form the coagulant as aluminium hydroxide. Further, the sludge of aluminium hydroxide particles and dye were observed at the water surface. The water became clear and colourless after sludge removal.

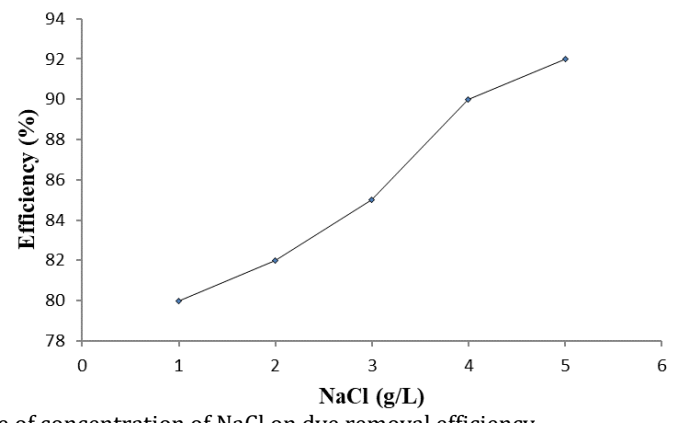

Fig. 6 Role of concentration of $\mathrm{NaCl}$ on dye removal efficiency

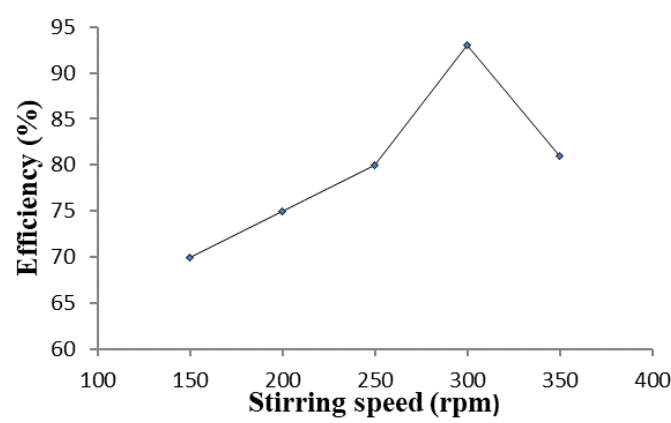

Fig. 7 Effect of stirring speed on dye removal efficiency

\subsubsection{Effect of Stirring Speed}

The main function of stirring is to ensure a good homogenization of the mixture dispersing the coagulant species in the reactor, thus causing efficient contact between the neutralized molecules and destabilized colloids and the cationic metallic species. Influence of stirring speed on https://doi.org/10.30799/jespr.187.19050406 colour removal efficiency was studied by varying the stirring speed from 150 to $350 \mathrm{rpm}$. Efficiency increases slightly when the stirring speed increases and attains its maximum at $300 \mathrm{rpm}$ (Fig. 7). After that the efficiency was decreased because of flocculation process allows the aggregation of colloidal particles into flocs which could hinder the removal process and has negative effect on colour removal.

\subsubsection{Effect of Inter Electrode Distance}

The distance between the electrodes is an important parameter implicated in the design of the electrochemical cell. Optimizing the inter electrode distance contributes to the regulation of the electrocoagulation process. To study the influence of electrode distance on dye removal efficiency, the distance between the electrodes was varied between 0.8 and $2.5 \mathrm{~cm}$ (Fig. 8). The removal efficiency is relatively low when the electrode distance was small due to short circuits when distance is above $2 \mathrm{~cm}$ and more energy was consumed in the EC process. Thus $2 \mathrm{~cm}$ inter electrode is maintained throughout the processes.

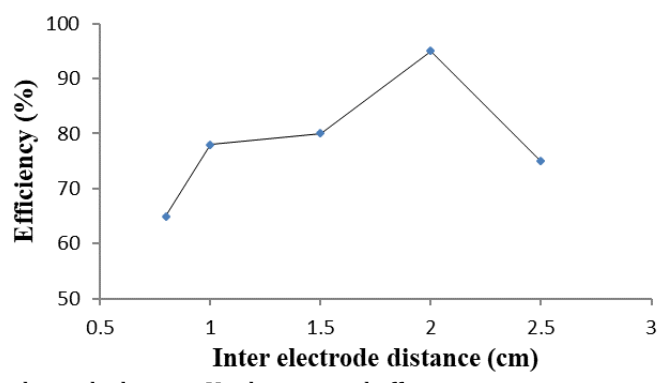

Fig. 8 Inter electrode distance Vs dye removal efficiency

\subsection{Enhanced Activity of Electrocoagulation using Graphene Oxide}

Graphene oxide (GO) is obtained by oxidation or sonication of graphite, and it possesses oxygen-containing functional groups, including hydroxyl groups $(-\mathrm{OH})$, epoxy groups $(-\mathrm{C}=\mathrm{O})$, and carboxyl groups $(-\mathrm{COOH})$. The presence of these functional groups enables the stable dispersion of GO in water and other polar organic solvents. GO also possesses a high specific surface area. Compared to other carbon-based materials, GO have better environmental compatibility and biocompatibility. Oxygen-containing functional groups can be used as the adsorption sites [27]. Through interaction with these oxygen-containing functional groups, dyes can be easily electrocoagulated.

The methylene blue dye solution of $0.25 \mathrm{~L}$ of $100 \mathrm{ppm}$ concentration and $0.01 \mathrm{~g}$ of grapheme oxide was added to the electrocoagulation reactor system. The operating factors were optimized fixed as current density 30 $\mathrm{mA} / \mathrm{cm}^{2}$, electrolysis time 20 minutes, $\mathrm{pH}$ of the medium $\mathrm{pH} 7.0$, stirring speed $300 \mathrm{rpm}$, inter electrode distance $2 \mathrm{~cm}$ and $\mathrm{NaCl}$ concentration 5.0 $\mathrm{g} / \mathrm{L}$. The temperature was maintained $25^{\circ} \mathrm{C}$. Fig. 9 shows the sludge formed after electrocoagulation with and without graphene oxide. At the end of experiment, the surface of Al electrodes was slightly decayed to produce the aluminium ions and form the coagulant as aluminium hydroxide. Further, the sludge of aluminium hydroxide particles and dye were observed at the bottom, as shown in Fig. 9. Finally, the water became clear and colourless after sludge removal.

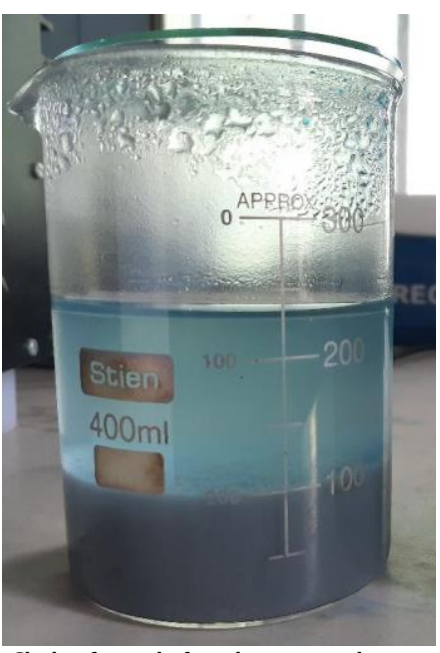

Sludge formed after electrocoagulation

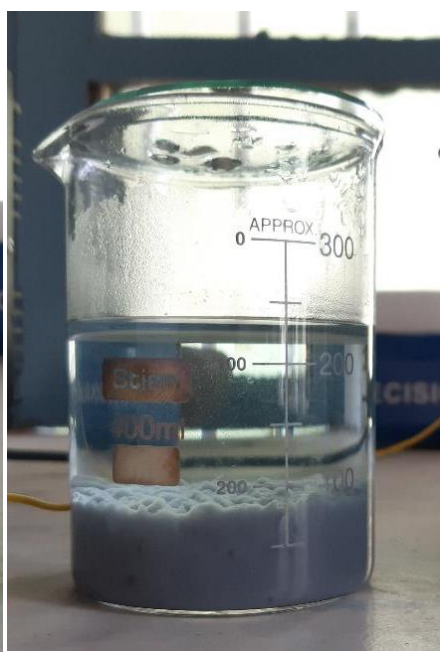

Sludge formed after electrocoagulation using graphene oxide as adsorbent
Fig. 9 Sludge formed after electrocoagulation with and without graphene oxide 


\section{Conclusion}

From the results obtained in the electrocoagulation process it was concluded that use of graphene oxide enhances the efficiency of dye removal process. The optimum operating parameters were found to be current density $30 \mathrm{~mA} / \mathrm{cm}^{2}$, electrolysis time 20 minutes, $\mathrm{pH}$ of the medium pH 7.0, stirring speed $300 \mathrm{rpm}$, inter electrode distance $2 \mathrm{~cm}$ and $\mathrm{NaCl}$ concentration $5.0 \mathrm{~g} / \mathrm{L}$. The sludge of aluminium hydroxide particles and dye were observed at the bottom and the water became clear and colourless after sludge removal. Thus, this process can be adopted for the effective removal of methylene blue from industrial effluents.

\section{Acknowledgement}

Author acknowledged her sincere gratitude to University Grant Commission (UGC), New Delhi for the financial assistance to conduct this research work under the scheme of Minor Research Project MRP-6421/16 (SERO/UGC) through UGC South Eastern regional Office (UGC-SERO).

\section{References}

[1] T.H. Kim, C. Park, E.B. Shin, S. Kim, Decolorization of disperse and reactive dyes by continuous electrocoagulation process, Desalination 150 (2002) 165-175.

[2] L.S. Perez, O.M. Rodriguez, S. Reyna, J.L. Sanchez-Salas, J.D. Lozada, M.A. Quiroz, E.R. Bandala, Phys. Chem. Earth 91 (2016) 53-60.

[3] M. Bayramoglu, M. Kobya, O.T. Can, M. Sozbir, Operating cost analysis of electrocoagulation of textile dye wastewater, Sep. Purif. Technol. 37 (2004) 117-125.

[4] G.H. Chen, Electrochemical technologies in wastewater treatment, Sep. Purif. Technol. 38 (2004) 11-41.

[5] M. Khemis, J.P. Leclerc, G. Tanguy, G. Valentin, F. Lapicque, Treatment of industrial liquid wastes by electrocoagulation: experimental investigations and an overall interpretation model, Chem. Eng. Sci. 61 (2006) 3602-3609.

[6] C.A. Martinez-Huitle, E. Brillas, Decontamination of wastewaters containing synthetic organic dyes by electrochemical methods: a general review, Appl. Catal. B 87 (2009) 105-145.

[7] S. Zodi, O. Potier, F. Lapicque, J.P. Leclerc, Treatment of the textile wastewaters by electrocoagulation: effect of operating parameters on the sludge settling characteristics, Sep. Purif. Technol. 69 (2009) 29-36.

[8] M. Carmona, M. Khemis, J.P. Leclerc, F.A. Lapicque, Simple model to predict the removal of oil suspensions from water using the electrocoagulation technique, Chem. Eng. Sci. 61 (2006) 1237-1246.

[9] M.H. El-Naas, S. Al-Zuhair, A. Al-Lobaney, S. Makhlouf, Assessment of electrocoagulation for the treatment of petroleum refinery wastewater, J. Environ. Manage. 91 (2009) 180-185.
[10] M. Bayramoglu, M. Eyvaz, M. Kobya, Treatment of the textile wastewater by electrocoagulation, Chem. Eng. J. 128 (2007) 155-161.

[11] M. Kobya, M. Bayramoglu, M. Eyvaz, Techno-economical evaluation of electrocoagulation for the textile wastewater using different electrode connections, J. Hazard. Mater. 148 (2007) 311-318.

[12] B.K. Korbahti, Response surface optimization of electrochemical treatment of textile dye wastewater, J. Hazard. Mater. 145 (2007) 277-286.

[13] M. Yousuf, A. Mollah, J.A.G. Gomes, K.K. Das, D.L. Cocke, Electrochemical treatment of Orange II dye solution - use of aluminum sacrificial treatment electrodes and floc characterization, J. Hazard. Mater. 174 (2010) 851-859.

[14] P. Gao, X. Chen, F. Shen, G. Chen, Removal of chromium (VI) from wastewate by combined electrocoagulation- electroflotation without a filter, Sep. Purif Technol. 43 (2005) 117-123.

[15] J.F. Martinez-Villafane, C. Montero-Ocampo, Optimisation of energy consumption in arsenic electro-removal from groundwater by the Taguchi method, Sep. Purif. Technol. 70 (2010) 302-305.

[16] T. Mariam, L.D. Nghiem, Landfill leachate treatment using hybrid coagulationnanofiltration processes, Desalination 250 (2010) 677-681.

[17] A.E. Yilmaz, R. Boncukcuoglu, M.W. Kocakerim, B. Keskinler, The investigation of parameters affecting boron removal by electrocoagulation method, J. Hazard. Mater. 125 (2005) 160-165.

[18] W. Ma, F.Q. Ya, M. Han, R. Wang, Characteristics of equilibrium kinetics studies for adsorption of fluoride on magnetic-chitosan particle, J. Hazard. Mater. 143 (2007) 296-302.

[19] A.K. Golder, N. Hridaya, A.N. Samanta, S. Ray, Electrocoagulation of methylene blue and eosin yellowish using mild steel electrodes, J. Hazard. Mater. 127(13) (2005) 134-140.

[20] Mohamed S. Mahmoud, Joseph Y. Farah, Taha E. Farrag, Enhanced removal of methylene blue by electrocoagulation using iron electrodes, Egypt. J. Petrol. 22(1) (2013) 211-216.

[21] Ningning Liu, Yunhai Wu, Removal of methylene blue by electrocoagulation: a study of the effect of operational parameters and mechanism, Ionics 25(8) (2019) 3953-3960.

[22] Tir, N. Moulai-Mostefa, M. Nedjhioui, Optimizing decolorization of methylene blue dye by electrocoagulation using Taguchi approach, Desal. Water Treat. 55(10) (2015) 2705-2710.

[23] M.A.M. Altufaily, A.A. Zahraa, De-colorization of methylene blue dye bearing waste by electrocoagulation technique, J. Eng. Appl. Sci. 13 (2018) 9524-9531.

[24] Farshid Ghanbari, Mahsa Moradi, Akbar Eslami, Mohammad Mahd Emamjomeh, Electrocoagulation/flotation of textile wastewater with simultaneous application of aluminum and iron as anode, Environ. Process. 1 (2014) 447-457.

[25] W. Pantorlao, D. Channei, W. Khanitchaidecha, A. Nakaruk, Decolorization of methylene blue solution by electrocoagulation using aluminum electrodes, Chiang Mai J. Sci. 45 (2018) 1-6.

[26] X. Duan, Pan Wu, Kewu Pi, Huiqin Zhang, Defu Liu, A.R. Gerson, Application of modified electrocoagulation for efficient color removal from synthetic methylene blue wastewater, Int. J. Electrochem. Sci. 13 (2018) 5575-5588.

[27] Imran Ali, Al Arsh Basheer, X.Y. Mbianda, Alexander Burakov, Evgeny Galunin, et al., Graphene based adsorbents for remediation of noxious pollutants from wastewater, Environ. Int. 127 (2019) 160-180. 